\title{
Synthesis and Properties of Polythiophène Benzylidene and Their Photovoltaic Applications
}

\author{
Reguig Bendoukha Abdelkarim ${ }^{1,3}$, Ahmed Yahiaoui ${ }^{1 *}$, Aïcha Hachemaoui ${ }^{1}$, Mohammed Belbachir ${ }^{2}$, \\ Abdelbasset Khelil ${ }^{3}$ \\ ${ }^{1}$ Laboratoire de chimie Organique, Macromoléculaire et des Matériaux (LCOMM), Université de Mascara, Faculté des Sciences \\ et de la Technologie, Mascara, Algérie; ${ }^{2}$ Laboratoire de Chimie des Polymères, Université d'Oran, Oran, Algérie; ${ }^{3}$ LPCM2E, \\ Universite' d'Oran Es-Senia, Algérie. \\ Email: *yahmeddz@yahoo.fr
}

Received March 19 ${ }^{\text {th }}, 2011$; revised April 11 ${ }^{\text {th }}, 2011$; accepted May $9^{\text {th }}, 2011$.

\begin{abstract}
Research on organic solar cells has a craze importance because they show very interesting properties including their flexibility and the opportunity to be made into large surfaces. However, their stability and performance should be significantly improved compared to their current state. A nominal output of around $10 \%$ will be the goal for the coming years. The use of organic materials for photovoltaic applications is the subject of intense research in recent years. This work is based in part on the development of new conjugated polymers. In this paper, we present the synthesis and characterization of poly [(thiophene-2,5-diyl)-co-(benzylidene)] PTB catalysed by Maghnite- $H^{+}$, used in the active layer of the solar cell organic heterojunction with PCBM (derivative of C60) was used as a junction of the solar cell: Glas/ITO/BCP/C60/PTB/Au/Al. A current density of short circuit of about $J c c 0.1 \mathrm{~mA} / \mathrm{cm}^{2}$ was obtained for this structure with a yield of around $0.15 \%$.
\end{abstract}

Keywords: Polymerization, Conjugated Polymers, UV-Vis Spectroscopy, IR Spectroscopy, Yield Calculation, Solar Cell Organic Heterojunction.

\section{Introduction}

In the past few decades, conjugated polymers with an extended p-conjugation have received considerable attention due to their electronic and photonic applications, such as light-emitting diodes [1,2], photovoltaic cells (PVCs) $[3,4]$, and thin film transistors [5,6]. Polythiophenes (PTs) are the most promising conjugated polymers because of their relatively high charge carrier mobility and long wavelength absorption in comparison withother conjugated polymers [7]. For example, regioregular poly(3-hexylthiophene) (P3HT) have exhibited excellent properties in PVCs $[8,9]$. However, P3HT only absorbs a part of the visible light and exhibits the relatively low open-circuit voltage (Voc) [10]. To further improve the related properties and explore the full potential applications of these materials, chemical modifications of PTs have been performed actively. One successful strategy to achieve broader absorption of PTs is based on the pioneering work by $\mathrm{Li}$ and coworkers $[11,12]$. They synthesized PTs with conjugated bi(thienylenevinylene) as side chain and made the absorption band in the region from $350 \mathrm{~nm}$ to $650 \mathrm{~nm}$, resulting in a good power conversion efficiency (PCE) of $3.18 \%$. PTs with substituents other than alkyl groups have also been investigated, among which those with electrondonating alkoxy groups have displayed promising optical properties [13].

Actually, the PCE of polymer photovoltaic devices is determined by three main factors: the efficiency of exciton generation, the efficiency of exciton dissociation into free charge carriers, and the efficiency of their unhindered collection by the electrodes. To increase the device efficiency, the active layer should absorb as many of the incident photons as possible to generate a maximum of excitons [14,15], therefore, low band gap polymers are necessary since the absorption of the active layer should match the solar spectrum well. The factors that influence the bandgap of a polymer are conjugated length, solid state ordering, and the presence of electron withdrawing or -donating moieties. The effective conjugated length, which is dependent upon the torsion angle between the repeating units along the polymer backbone, can be controlled by choosing sterically hindered units along the polymer back-chain or by introducing bulky side-chains 
to twist the units out of plane $[16,17]$. While, the Voc of a PVCs based on polymer and (6,6)-phenyl C61-butyric acid methyl ester (PCBM) blend system is determined by the difference between the HOMO of the polymer and lowest unoccupied molecular orbital (LUMO) of PCBM $[18,19]$. Therefore, the HOMO level is also an important parameter to be considered when designing a new electron-donating polymer.

Triphenylamine (TPA) is a preferred electrondonating moiety with excellent hole transporting properties and their derivatives have been widely investigated for almost two decades [20,21]. Owing to the noncoplanarity of the three phenyl substituents, TPA derivatives can be viewed as $3 \mathrm{D}$ systems and the amorphous character of these materials offers possibilities to developactive materials for PVCs with isotropic optical and charge-transport properties [22]. Recently, Roncali, J. and coworkers [23] synthesized various series of star-shaped molecules based on TPA small molecules with combinations of thienylenevinylene conjugated branches and lectronwithdrawing indanedione or dicyanovinyl groups, which have been applied to organic PVCs as donor materials and got PCE of $1.20 \%$.To our knowledge, the application of TPA-based polymers for photovoltaic devices has been scarcely considered.

Here, we report the synthesis and photovoltaic properties of a new conjugated polymer derived from PT, poly [(thiophene-2,5-diyl)-co-(benzylidene)] (PTB) a novel soluble obtained in a single step polymerization through a very simple acid-catalyzed condensation of thiophene and benzaldehyde in the presence of an exchanged clay montmorillonite called Mag-H as catalyst. The PTB was used for the photoactive layer; ITO and aluminum (Al) are used as metal electrodes.

Poly [(thiophene-2,5-diyl)-co-(benzylidene)]PTB is soluble in dichloromethane $\mathrm{CH} 2 \mathrm{Cl} 2$, was characterized by infrared spectroscopy and Ultra violet spectroscopy.

\section{Experimental}

\subsection{Reagents}

Dichloromethane and methanol (98\%) were purchased from Aldrich and used as received. Thiophene: was purchased from Aldrich Chemical Co. and distilled under reduced pressure. Benzaldehyde: was purchased from Aldrich Chemical. Raw-Maghnite (Algerian montmorillonite clay) was procured from BENTAL (Algerian Society of Bentonite).

\subsection{Polymer Preparatio}

The condensation of benzaldehyde with thiophene in the presence of $\mathrm{Mag}-\mathrm{H}^{+}$as a catalyst was carried out by condensation in bulk under nitrogen for $6 \mathrm{~h}$.
Each mixture was prepared with a weighted quantity of Mag- $\mathrm{H}^{+}$dried just before use for $1 \mathrm{~h}$ in a drying oven at $100^{\circ} \mathrm{C}$. Benzaldehyde $\left(6 \times 10^{-3} \mathrm{~mol}\right)$ and thiophene $(6$ $\times 10^{-3} \mathrm{~mol}$ ) were mixed and $1 \mathrm{~g}$ of $\mathrm{Mag}-\mathrm{H}^{+}$was added. The reaction was carried out at $25^{\circ} \mathrm{C}$ for $6 \mathrm{~h}$. The polymer film was washed with water and methanol several times, and finally dried under vacuum at room temperature for $24 \mathrm{~h}$. The yield was $50 \%$. The resulting polymers were characterized by FTIR and UV-Visible spectroscopy.

Anal. Calcd for (C22H14S2)n C, 77.16; H, 4.12; S, 18.72. Found: C, 78.63; H, 4.53; S, 15.93. IR (film on $\left.\mathrm{NaCl}, \mathrm{cm}^{-1}\right): 3027,1598,1492,1443,1294,1231,1176$, 1155, 1105, 1073, 1028, 901, 801, 751, 696, 668 (Figure 1).

\subsection{Development of the Photovoltaic Cell}

Photovoltaic cells consist of a molecular active layer sandwiched between an anode of ITO (thickness $100 \mathrm{~nm}$ ) and an aluminum cathode. The cell size was determined by the size of the aluminum cathode (evaporated through a mask of $0.25 \mathrm{~cm}^{2}$ ). A layer $260 \AA$ béthocuproine $\mathrm{PCO}$ $\left(\mathrm{C}_{26} \mathrm{H}_{2} \mathrm{ON}_{2}\right)$, sandwiched between the ITO layer and the acceptor is primarily intended to protect this last layer of oxygen diffusion from ITO. Toward the cathode, a layer of $20 \AA$ of gold $(\mathrm{Au})$ avoids the recombination of excitons in organic-metal interface (Figure 3). The bathocuproine BCP thickness and C60 respectively 260 and $1650 \AA$ were being deposited on the ITO layer in the laboratory by the technique of thermal evaporation (TE).

We conducted the following cells, using the active layer in the donor-acceptor pair TMP-C60:

The layer of PTB was dissolved in a solution of dichloromethane and deposited onto the layer of C60 by the method of spin coating.

So we made a solar cell junction with the following: Glass/ITO/BCP/ C60/PTB/Au/Al

\section{Results and Discussion}

\subsection{Spectroscopic Characterization:}

The Figure 1 presents the FTIR spectrum of PTB and shows the appearance of a strong absorption at $1640 \mathrm{~cm}^{-1}$ which is attributed to the stretching vibration of conjugated $\mathrm{C}=\mathrm{C}$ and the stretching vibration of aromatic in thiophene .A distinct peack near $737,37 \mathrm{~cm}^{-1}$ is due the out of plane vibration $\mathrm{C} \beta-\mathrm{H}$ characteristic of the $\alpha$-linkage in thiophene rings .

The UV-vis absorption spectra were recorded with an OPTIZEN UV-2120 spectrophotometer (Figure 2) shows the optical absorption spectrum of polymer: PTB in $\mathrm{CH} 2 \mathrm{Cl} 2$ solution. The colours of the polymer solutions were almost grey or black. The absorption spectrum in 


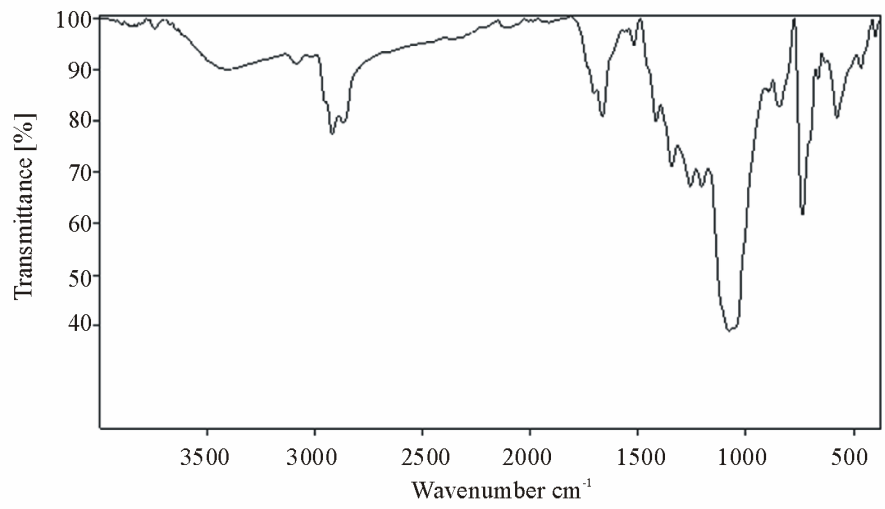

Figure 1. FTIR spectrum of PTB.

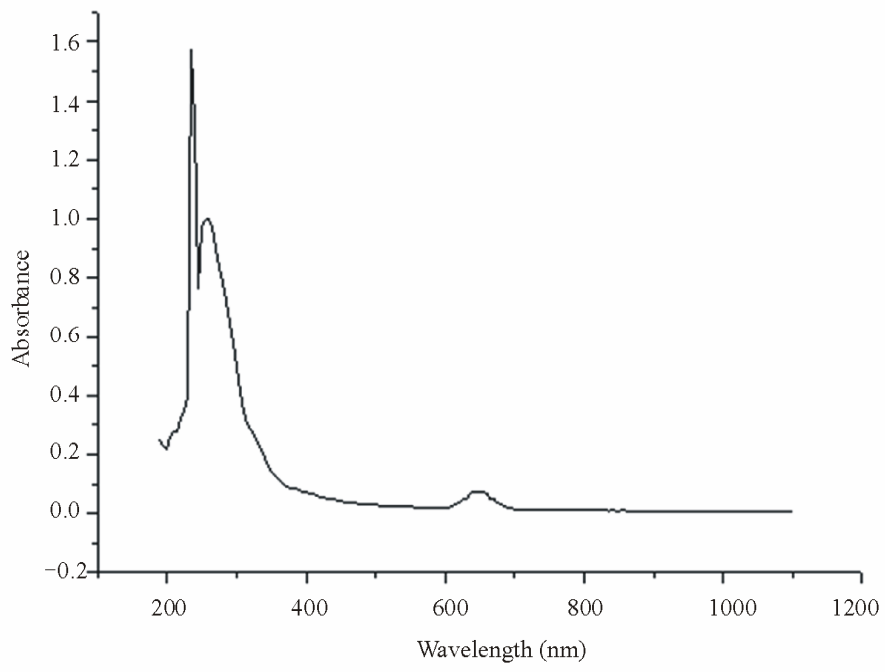

Figure 2. Optical absorption spectra of PTTM in $\mathrm{CH}_{2} \mathrm{Cl}_{2}$.<smiles>CC(C)(C)c1ccccc1C(C)(C)C</smiles>

(a)

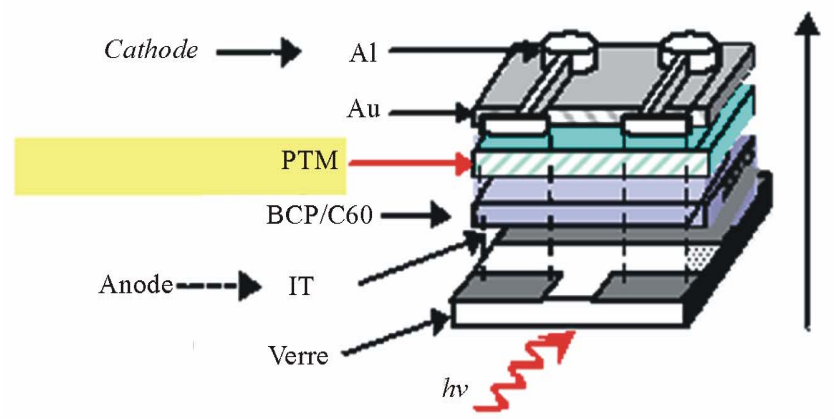

(b)

Figure 3. (a) Molecular structure of PTB, (b) structure of printed diodes with "P N" junction 
Figure 2 shows two major absorption bands. The band in range of $280-300 \mathrm{~nm}$ is assigned to the $\pi-\pi^{*}$ transition of the aromatic heterocyclic since it corresponds to the same band as its precursor, and the band in the range of $620-650 \mathrm{~nm}$ is assigned to the $\pi-\pi^{*}$ band gap transition [9].

\subsection{Photovoltaic Properties}

To investigate the photovoltaic properties of the polymers, the bulk heterojunction solar cells with a structure of $\mathrm{ITO} / \mathrm{BCP} / \mathrm{C} 60 / \mathrm{PTB} / \mathrm{Au} / \mathrm{Al}$ were fabricated where the polymer was used as donor and $\mathrm{C} 60$ as acceptor. The active layers were prepared by spin coating

Current-voltage characteristics of solar cells in the dark and under illumination of $100 \mathrm{~mW} / \mathrm{cm}^{2}$ white light from a xenon lamp (Jobin Yvon, FL-1039) were measured on the computer-controlled Keithley 2400 SourceMeter system measurement. All measurements were carried out under ambient atmosphere at room temperature.

The Current-voltage characteristics in the dark and under illumination were measured. One can see that in our case (Figure 4) a photovoltaic effect is revealed but with a small but significant yield was obtained. This structure has a good recovery, a VOC of $0.26 \mathrm{~V}$ and a JSC $1,6 \mathrm{~mA} / \mathrm{cm}^{2}$. In addition, there is a clear improvement of the FF (36\%), giving a yield of around $0.15 \%$.

After a performing a photovoltaic cells, and in order to well understand and control the key physical processes that determine the performance of organic solar cells, we must know all the physical parameters, such as series resistance, parallel resistance, the different saturation currents, photo-current and ideality factor.

We were led to use electrical models [24], equivalent circuit to a diode, which allowed us to model our solar cells in the dark and under illumination.

\subsection{Electrical Equivalent Circuit of a Photoelectric Cell}

Solar cells are generally equivalent to a simple circuit with a single diode in parallel with a resistor $\mathrm{Rp}$, and a series resistance Rs .

In literature, the most frequent expression is:

$$
I=I_{S}\left[\exp \left(\frac{V-R_{S} I}{n u_{T}}\right)-1\right]+\frac{V-R_{S} I}{R_{p}}
$$

where $\mathrm{n}$ is the ideality coefficient.

The solution of equation (1) is:

$V=\left(R_{S}+R_{p}\right) I+R_{p} I_{S}-n u_{T} W\left[\frac{R_{p} I_{S}}{n u_{T}} \exp \left(\frac{R_{p}\left(I+I_{S}\right)}{n u_{T}}\right)\right]$

where $\mathrm{W}$ is the Lambert function defined by

$$
W(x) e^{W(x)}=x .
$$

\subsection{In the Case of the Diode Under Illumination}

PN junction under illumination can be diagrammed by a current generator Iph (current proportional to incident light) in parallel with the diode delivering a current

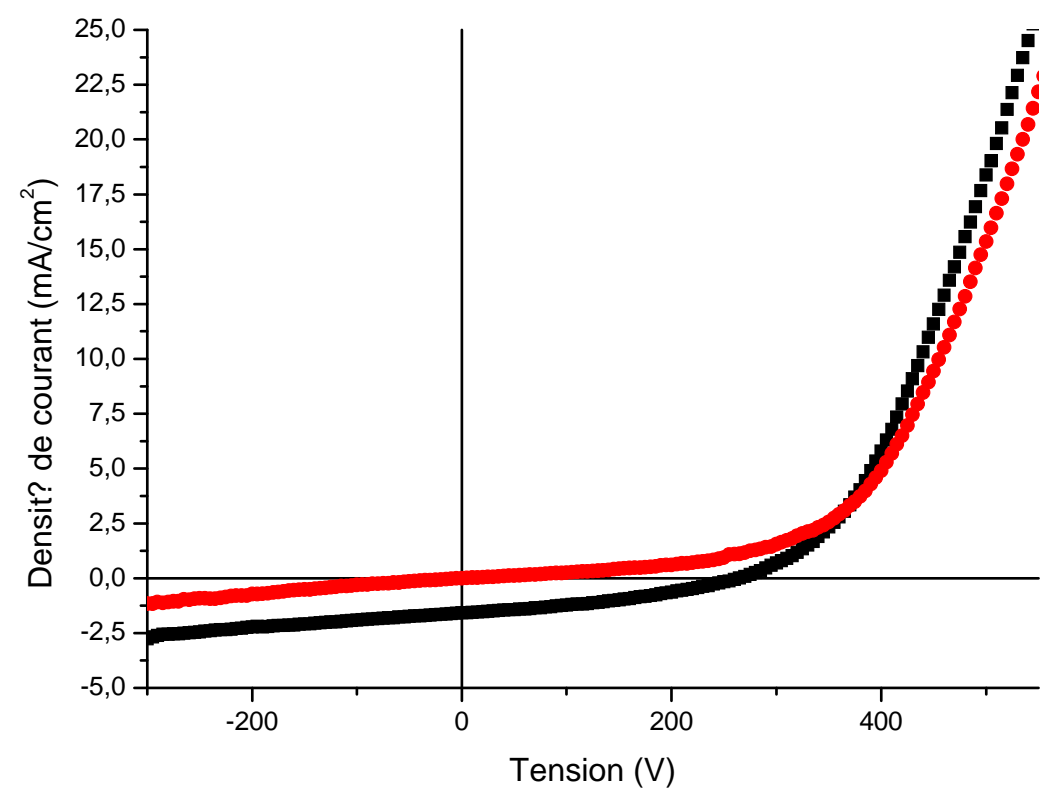

Figure 4. Current-voltage characteristics of polymer photovoltaic cells based on PTB (Substrate/ ITO / PCB /C60 /PTB/ Al) blend system in the dark (-- --) and underillumination (-- --) of $100 \mathrm{~mW} / \mathrm{cm} 2$ white light. 


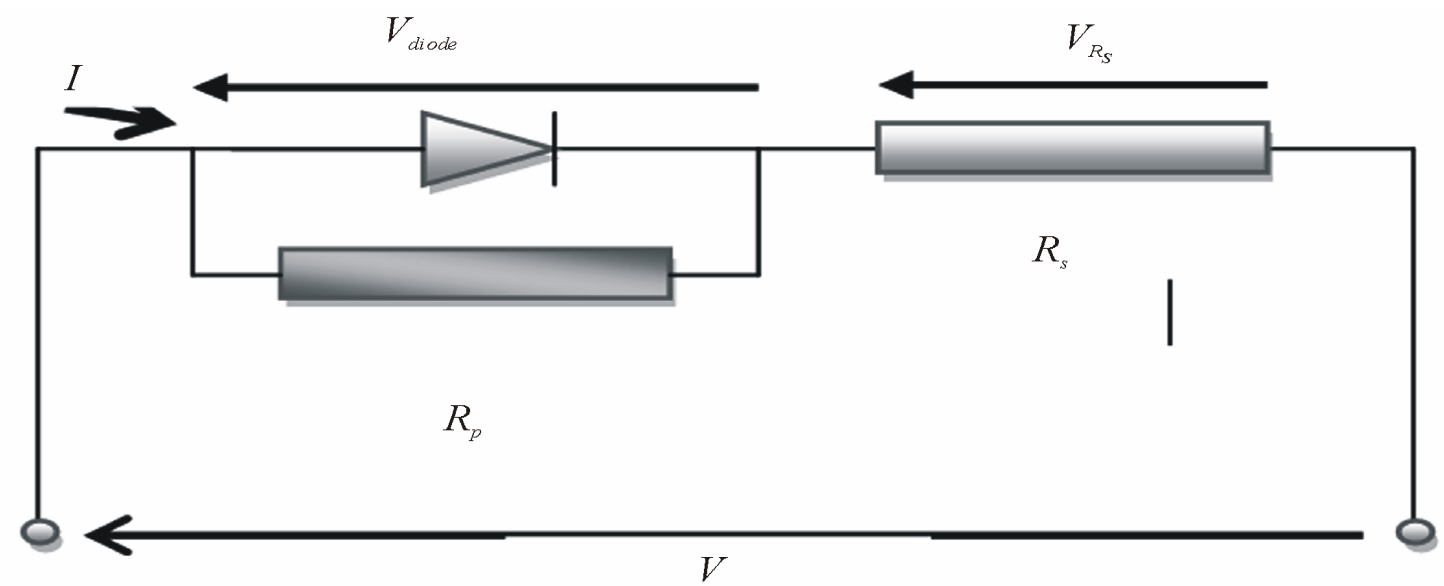

Figure 5. Diagram of a real diode.

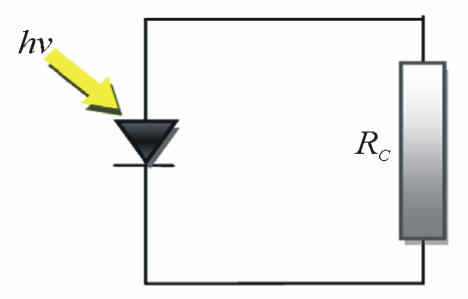

(a)

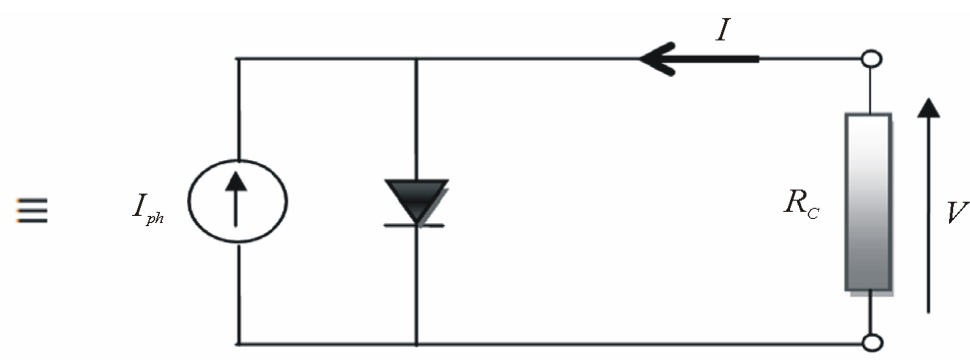

(b)

Figure 6 electric circuit of a PN junction under ideal illumination (a) connected to a load resistor and its equivalent circuit (b).

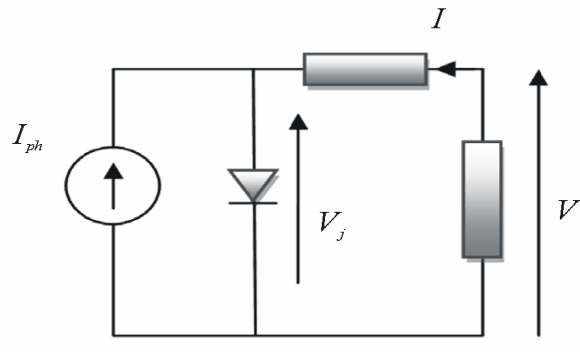

(a)

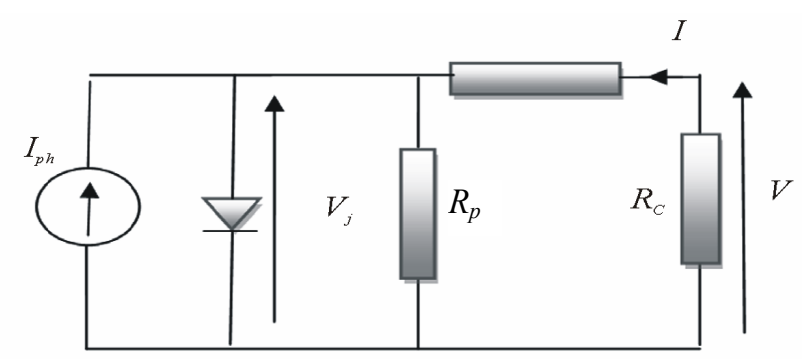

(b)

Figure 7. Case of a PN junction with a series resistance (a) and shunt resistor in series (b).

$$
i=I_{S}\left[\exp \left(\frac{q V}{k T}\right)-1\right] \text { (darkness). }
$$

The overall current is given by the following equation:

$$
I=I_{S}\left[\exp \left(\frac{q V}{k T}\right)-1\right]-I_{p h}
$$

We obtain the following equivalent circuit of an idéal solar cell (Figure 6).

When the junction is connected to a load resistor $R_{C}$, the flow current through $R_{C}$ brings up a voltage drop (open circuit, $R_{C} \rightarrow \infty$ et $V=V_{C O}$ ).

The orientation of the current $I_{p h}$ to $R_{C}$ produces a voltage $V$ inducing a bias across the junction so that the current $I$ is opposite to $I_{p h}$

From another point of view, we can consider that the direction of photo-current in the load resistance induces a voltage across the junction which generates a direct current $I$ in the opposite direction $I_{p h}$, so that, generally we dont observe the entire current $I_{p h}$, but only the quantity:

$$
I=i-I_{p h}
$$

\subsection{Real IV Characteristic of a Photovoltaic Cell}

When the contact resistance (resistivity electrodes and interfaces metal-organic materials) and ohmic losses (due to the resistivity of the organic layers) generate signifi- 
cant resistance from the load resistor, we must associate series resistance $R_{S}$ in the equivalent circuit.

If we denote $V j$ the voltage across the junction, the voltage $\mathrm{V}$ across the cell is reduced to:

$$
V=V_{j}+R_{S} I
$$

In the first quadrant we have:

$$
I=I_{S}\left[\exp \left(\frac{q V}{k T}\right)-1\right]-I_{p h}=\left[\exp \left(q \frac{V-R_{S} I}{k T}\right)-1\right]-I_{p h}
$$

In addition, when leak currents occur through the cell, we can take into account this new component by inserting a parallel resistance $(\mathrm{Rp})$. When this resistance becomes very large $(\mathrm{Rp} \rightarrow \infty)$, these leak currents become negligible $i_{p} \approx 0$. We obtain:

$$
I=I_{S}\left[\exp \left(q \frac{V-R_{S} I}{k T}\right)-1\right]-I_{p h}+\frac{V-R_{S} I}{R_{p}}
$$

Already in the case of an ideal cell we do not find the total current $I=i-I_{p h}$ but only i-ph. In the real case this reduction is quite pronounced, this is due to the shunt resistor $R_{p}$ which introduces a leak current $i_{p}$ and is given by the following equation:

$$
I=i-I_{p h}+i_{p}
$$

Solar cells are generally equivalent to a simple circuit with a single diode in parallel with a resistor $R_{p}$, and a resistor $R_{S}$ in series.

$$
\begin{aligned}
& I=I_{S}\left[\exp \exp \left(\frac{V-R_{S} I}{n u_{T}}\right)-1\right]+\frac{V-R_{S} I}{R_{p}}-I_{p h} \\
& V=\left(R_{S}+R_{p}\right) I+R_{p}\left(I_{p h}+I_{S}\right) \\
& +n u_{T} W\left\{\frac{R_{p} I_{S}}{n u_{T}} \exp \left[\frac{R_{p}\left(I+I_{S}-I_{p h}\right)}{n u_{T}}\right]\right\}
\end{aligned}
$$

With n: ideality factor,

$$
u_{T}=\frac{k T}{q}, W=\text { Lambert Function }
$$

\subsection{Theoretical Simulations to Determine the Parameters.}

We performed theoretical calculations of simulations to determine the parameters of the I-V curve under illumination (Figure 8).

The analytical simulations were used to calculate the values of various parameters. The performed values are in good agreement with experimental results. According to values found from the filted curve on the experimental curve (under illumination), we can confirm that we have a good diode. The yield of $0.15 \%$ is confirmed by these values.

In conclusion, we have prepared some conjgugated poly(thiophene benzylidene) by polycondensation of benzaldehyde and thiophene catalyzed by Maghnite-H+, the conjugated aromatic backbone through the insertion

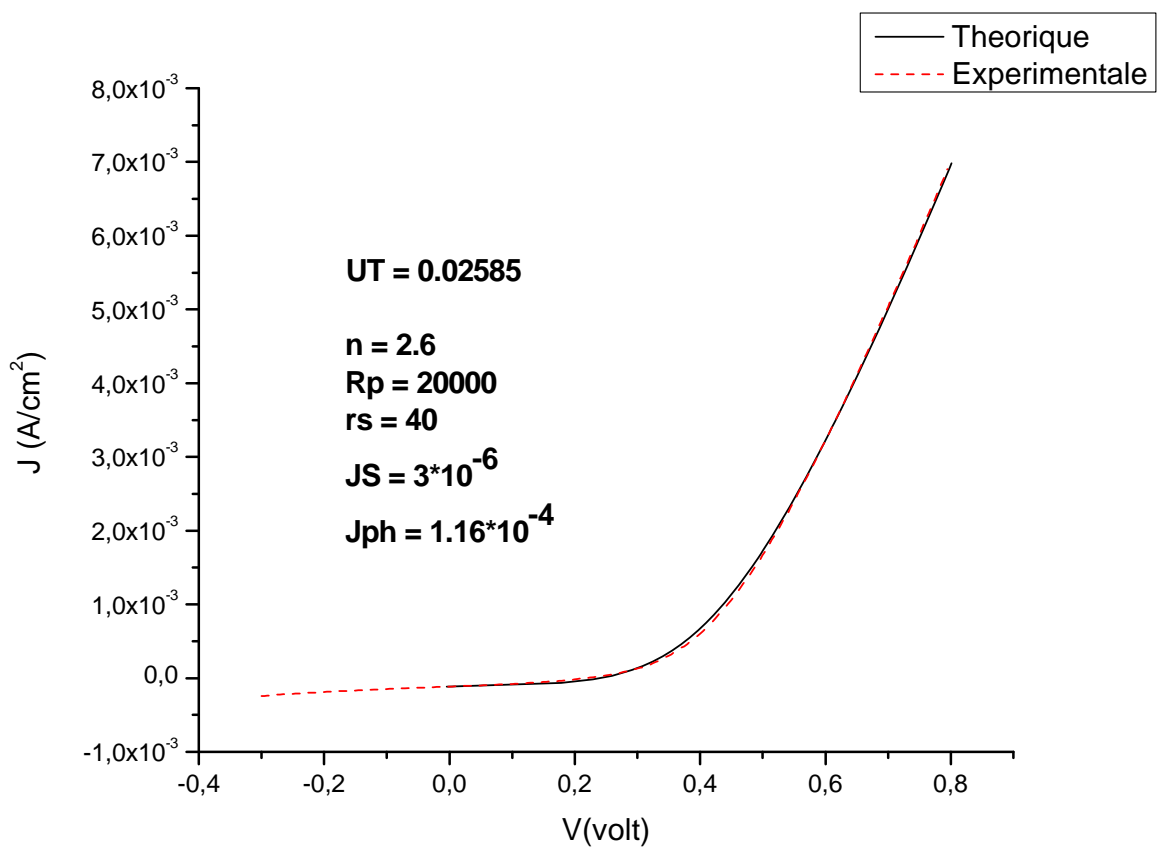

Figure 8. Current-voltage characteristics of polymer photovoltaic cells based on PTB (Substrate/ ITO / PCB /C60 /PTB/ Al) blend system (----)experimentaland ( ) theoretical curves. 
Table 1. Photovoltaic Characteristics of our Polymer and those of literature [25].

\begin{tabular}{ccccc}
\hline & Voc $(\mathrm{V})$ & Jsc $(\mathrm{mA} / \mathrm{cm} 2)$ & FF & 0.36 \\
PTB & 0.26 & 1.6 & 0.32 & 0.15 \\
P3T-DDTPA & 0.72 & 0.38 & 0.24 & 0.086 \\
P1 & 0.71 & 0.08 & 0.25 & 0.011 \\
P2 & 0.74 & 0.12 & 0.25 & 0.013 \\
P3 & 0.74 & 0.10 & 0.019 & 0.25 \\
\hline
\end{tabular}

PTB: poly (thiophene-co-benzylidene 1:1)

P3T-DDTPA: Poly ((E)-4-(dodecyloxy)-N-(4-(dodecyloxy)phenyl)-N-(thiophen-3-yl)vinyl)phenyl)aniline)

P1: poly ((E)-4-(2-(2,5-Dibromothiophen-3-yl)vinyl)-N,Nbis(4-(dodecyloxy)phenyl)aniline-co-3-hexylthiophene 10:1)

P2: poly ((E)-4-(2-(2,5-Dibromothiophen-3-yl)vinyl)- $N$,Nbisidodecyloxy)phenyl)aniline-co-3-hexylthiophene 2:1)

P3: poly ((E)-4-(2-(2,5-Dibromothiophen-3-yl)vinyl)- $N$,Nbis(4-(dodecyloxy)phenyl)aniline-coi3-hexylthiophene 1:1)

P4: poly ((E)-4-(2-(2,5-Dibromothiophen-3-yl)vinyl)-N,Nbis(4-(dodecyloxy)phenyl)aniline-co-3-hexylthiophene 1:4.8)

of benzylidene between two thiophene rings.

Such results may serve primarily to illustrate a new strategy to increase the low band gap polymers through the arrangement of different aromatic heterocyclic in conjugated polymer backbones.

The manufacture of organic solar cell with heterojunction, Glass/ITO/BCP/C60/PTB/Au/Al shows that our cell is Promising with a VOC of $0.26 \mathrm{~V}$ and a $1.6-\mathrm{JSC} \mathrm{mA} / \mathrm{cm}^{2}$. In addition, there is a clear improvement of the FF (36\%), giving a yield of about $0.15 \%$. PTB gave the best results compared to the 3-hexylthiophene copolymers [25], with the PCE of $0.15 \%$ because of the relative low HOMO level of the polymer. We note here that this high efficiency is obtained due to the high Jsc and Voc. photovoltaic parameters are summarized in Table 1.

These results it was confirmed by calculations of theoretical simulations to determine the parameters of the curve under illumination. Further improvements could be made for the PTB from these polymers by optimizing the polymer/C60 entering the morphology of the active layer

\section{Acknowledgements}

The authors wish to thank the National Agency for Development and Research of Algeria for the financial support.

\section{REFERENCES}

[1] A. J. Heeger, "Semiconducting and Metallic Polymers: The Fourth Generation of Polymeric Materials Angew. Chem Int Ed Engl," National Center for Biotechnology Information, Vol. 40, July 2001, pp. 2591-2611.

[2] L. Liao, A. Cirpan, Q. Chu, F. E. Karase and Y. J. Pang, "Synthesis and Optical Properties of Light-Emitting $\pi$-Conjugated Polymers Containing Biphenyl and Dithienosilole," Journal of Polymer Science Part A: Polymer Chemistry, Vol. 45, No. 10, May 2007, pp. 2048-2058. doi:10.1002/pola.21970

[3] G. Yu, J. Gao, J. C. Hummelen, F. Wudl and A. J. Heeger, "Polymer Photovoltaic Cells: Enhanced Efficiencies via a Network of Internal Donor-Acceptor Heterojunctions," Science, Vol. 270, No. 5423, December 1995, pp. 17891791.

\section{doi:10.1126/science.270.5243.1789}

[4] E. J. Zhou, Z. A. Tan, Y. J. He, C. H. Yang and Y. F. Li, "Synthesis, Hole Mobility and Photovoltaic Properties of Two Alternating Poly[3-(Hex-1-Enyl)Thiophene-CoThioph-Ene]s," Journal of Polymer Science Part A: Polymer Chemistry, Vol. 45, February 2007, pp. 629-638.

[5] T. T. M. Dang, S. J. Park, J. W. Park, D. S. Chung, C. E. Park, Y. H. Kim and S. K. Kwon, "Synthesis and Characterization of Poly(benzodithiophene) Derivative for Organic Thin Film Transistors," Journal of Polymer Science Part A: Polymer Chemistry, Vol. 45, November 2007, pp. 5277-5284. doi: $10.1002 /$ pola. 22272

[6] E. Lim, Y. M. Kim, J. I. Lee, B. J. Jung, N. S. Cho, J. Lee, L. M. Do and H. K. Shim, "Relationship between the Liquid Crystallinity and Field-Effect-Transistor Behavior of Fluorene-Thiophene-Based Conjugated Copolymers," Journal of Polymer Science Part A: Polymer Chemistry, Vol. 44, August 2006, pp. 4709-4721. doi: $10.1002 /$ pola. 21586

[7] W. S. Shin, S. C. Kim, S.J. Lee, H.S. Jeon, M. K. Kim, B.V.K. Naidu, S.H. Jin, J.K. Lee, J.W. Lee, Y.S. Gal, "Synthesis and Photovoltaic Properties of a Low-Band-Gap Polymer Consisting of Alternating Thiophene and Benzothiadiazole Derivatives for Bulk-Heterojunction and Dye-Sensitized Solar Cells," Journal of Polymer Science Part A: Polymer Chemistry, Vol. 45, April 2007, pp. 1394-1402. doi:10.1002/pola.21909

[8] M. Reyes-Reyes, K. Kim and D. L. Carroll, "High-Efficiency Photovoltaic Devices Based on Annealed Poly(3-hexylthio-phene) and 1-(3-Methoxycarbonyl)-Propyl-1-Phenyl$(6,6)$ C61 Blends," Applied Physics Letters, Vol. 87, August 2005, pp. 83506-83508. doi:10.1063/1.2006986

[9] F. Monestier, J.-J. Simon, P. Torchio, L. Escoubas, F. Flory and S. Bailly, "Remi de Bettignies, Stephane Guillerez, Christophe Defranoux, Modeling the Short-Circuit Current Density of Polymer Solar Cells based on P3HT: PCBM Blend," Solar Energy Materials and Solar Cells, Vol. 91, No. 5-6, 2007, pp. 405-410. doi:10.1016/j.solmat.2006.10.019

[10] W. L. Ma, C. Y. Yang, X. Gong, K. Lee and A. J. Heeger, "Thermally Stable, Efficient Polymer Solar Cells with Nanoscale Control of the Interpenetrating Network Mor- 
phology," Advanced Functional Materials, Vol. 15, October 2005, pp. 1617-1622.

doi:10.1002/adfm.200500211

[11] J. H. Hou, Z. A. Tan, Y. J. He, C. H. Yang and Y. F. Li, "Branched Poly(Thienylene Vinylene)s with Absorption Spectra Covering the Whole Visible Region," Macromolecules, Vol. 39, No. 14, July 2006, pp. 4657-4662. doi:10.1021/ma060662u

[12] J. H. Hou, Z. A. Tan, Y. Yan, Y. J. He, C. H. Yang and Y. F. Li, "Synthesis and Photovoltaic Properties of Two-Dimensional Conjugated Polythiophenes with Bi(ThienylenevInylene) Side Chains," Journal of American Chemical Society, Vol. 128, No. 14, April 2006, pp. 4911-4916. doi:10.1021/ja060141m

[13] C. J. Shi, Y. Yao, Y. Yang and Q. B. Pei, "Regioregular Copolymers of 3-Alkoxythiophene and Their Photovoltaic Application," Journal of American Chemical Society, Vol. 128, No. 27, July 2006, pp. 8980-8986. doi:10.1021/ja061664x

[14] F. L. Zhang, M. Johansson, M. R. Andersson, J. C. Hummelen and S. O. Ingana, "Polymer Solar Cells Based on MEH-PPV and PCBM," Synth MetZhang, Vol. 137, April 2003, pp. 1401-1402. doi:10.1016/S0379-6779(02)01059-7

[15] K. F. Cheng, C. L. Liu and W. C. Chen, "Small Band Gap Conjugated Polymers based on Thiophene-Thienopyrazine Copolymers," Journal of American Chemical Society, Vol. 45, October 2007, pp. 5872-5883. doi:10.1002/pola.22339

[16] M. R. Andersson, O. W. Thomas, Mammo, M. Svensson, M. Theander and S. O. Ingana, "Substituted PolythioPhenes Designed for Optoelectronic Devices and Conductors," Journal of Material Chemistry, Vol. 9, 1999, pp. 1933-1940. doi:10.1039/a902859e

[17] E. Perzon, X. J. Wang, S. Admassie, S. O. Ingana and M. R. Andersson, "An alternating Low Band-Gap Polyfluorene for Optoelectronic Devices," Polymer, Vol. 47, May 2006, pp. 4261-4268. doi:10.1016/j.polymer.2006.03.110

[18] C. J. Brabec, N. S. Sariciftci and J. C. Hummelen, "Plastic Solar Cells," Advanced Functional Materials, Vol. 11, February 2001, pp. 15-26. doi:10.1002/1616-3028(200102)11:1<15::AID-ADFM15 $>3.0 . \mathrm{CO} ; 2-\mathrm{A}$
[19] S. E. Shaheen, C. J. Brabec, N. S. Sariciftci, F. Padinger, T. Fromerz and J. C. Hummelen, "2.5\% Efficient Organic Plastic Solar Cells," Applied Physics Letters, Vol. 78, December 2001, pp. 841-843. doi:10.1063/1.1345834

[20] C. H. Kuo, W. K. Cheng, K. R. Lin, M. K. Leung and K. H. Hsieh, "High-Efficiency Poly(phenylenevinylene)-coFluorene Copolymers Incorporating a Triphenylamine as the End Group for White-Light-Emitting Diode Applications," Journal of Polymer Science Part A: Polymer Chemistry, Vol. 45, October 2007, pp. 4504-4513. doi: $10.1002 /$ pola. 22194

[21] S. K. Lee, T. Ahn, N. S. Cho, J. I. Lee, Y. K. Jung and J. Lee, H. K. Shim, "Synthesis of New Polyfluorene Copolymers with a Comonomer Containing Triphenylamine Units and Their Applications in White-Light-Emitting Diodes," Journal of Polymer Science Part A: Polymer Chemistry, Vol. 45, April 2007, pp. 1199-1209. doi:10.1002/pola.21892

[22] L. J. Huo, C. He, M. F. Han, E. J. Zhou and Y. F. Li, "Alternating Copolymers of Electron-Rich Arylamine and Electron-Deficient 2,1,3-Benzothiadiazole: Synthesis, Characterization and Photovoltaic Properties," Journal of Polymer Science Part A: Polymer Chemistry, Vol. 45, September 2007, pp. 3861-3871. doi:10.1002/pola.22136

[23] S. Roquet, A. Cravino, P. Leriche, O. Aleveque, P. Frere and J. Roncali, "Triphenylamine-Thienylenevinylene Hybrid Systems with Internal Charge Transfer as Donor Materials for Heterojunction Solar Cells," Journal of Polymer Science Part A: Polymer Chemistry, Vol. 128, March 2006, pp. 3459-3466. doi:10.1021/ja058178e

[24] B. Kouskoussa, M. Morsli, K. Benchouk, G. Louarn, L. Cattin, A. Khelil and J. C. Bernede, "On the Improvement of the Anode/Organic Material Interface in Organic Solar Cells by the Presence of an Ultra-Thin Gold layer," Physical Status Solidity, Vol. 206, February 2009, pp. 311315.

[25] Y. Li, L. Xue, H. Xia, B. Xu, S. Wen and W. Tian, "Synthesis and Properties of Polythiophene Derivatives Containing Triphenylamine Moiety and Their Photovoltaic Applications," Journal of Polymer Science Part A: Polymer Chemistry, Vol. 46, 2008, pp. 3970-3984. doi:10.1002/pola. 22737 